\title{
Clinical Characteristics and Outcomes of the First Episode of Urinary Tract Infection in Neonates and Infants Younger than 2 Months of Age
}

\section{Jackie Ying-Wai Cheng, MRCPCH, $\mathrm{DCH}$}

Department of Paediatrics and Adolescent Medicine, Pamela Youde Nethersole Eastern Hospital, Chai Wan, Hong Kong

\section{Corresponding author: \\ Jackie Ying-Wai Cheng, MRCPCH, DCH \\ Department of Paediatrics and \\ Adolescent Medicine, Pamela Youde \\ Nethersole Eastern Hospital, 3 Lok Man \\ Road, Chai Wan, Hong Kong S.A.R., P.R.C. \\ Tel: +852-9663-7978 \\ E-mail:jackieyg@gmail.com}

Received: 24 August 2017

Revised: 18 September 2017

Accepted: 27 September 2017

\footnotetext{
This is an open-access article distributed under the terms of the Creative Commons Attribution Non-Commercial License (http:// creativecommons.org/licenses/by-nc/4.0/) which permits unrestricted non-commercial use, distribution, and reproduction in any medium, provided the original work is properly cited.
}

Purpose: The American Academy of Pediatrics provides guidelines for managing febrile urinary tract infection (UTI) in infants and children 2-24 months old, but little guidance is offered regarding UTIs in those younger than 8 weeks of age. The definition of UTI is unclear and whether to proceed with micturating cystourethrography (MCUG) or ${ }^{99 m}$ technetium-dimercaptosuccinic acid (DMSA) scintigraphy scan in this age group is controversial.

Methods: We retrospectively analyzed 29 neonates and infants younger than 2 months of age who underwent late DMSA scans 9 months following the first episode of febrile or symptomatic UTI between July 2009 and June 2016.

Results: In total, 192 children aged 0-24 months underwent ultrasound and DMSA scans (MCUG in 174/192). Neonates and infants younger than 2 months of age were significantly less likely to develop fever, and had a lower fever peak, shorter duration of fever before admission and after starting antibiotics, longer hospitalization period, lower C-reactive protein, and greater incidence of nonEscherichia coli infection. There was no difference in pyuria response at diagnosis. The prevalence rates of an ultrasound abnormality (28\%), vesicoureteral reflux $(28 \%)$, UTI recurrence (38\%), and renal scarring (10\%) in infants younger than 8 weeks of age were similar to those in children 2-24 months old.

Conclusion: Neonates and infants younger than 2 months of age with UTI warrant special consideration because the fever response used for diagnosis in older children may be absent or blunted. Clinical guideline is needed for the diagnosis and management of UTI in this age group.

Key words: Urinary tract infection, Neonates, Fever, DMSA, MCUG

\section{Introduction}

Urinary tract infection (UTI) is a common bacterial illness in childhood ${ }^{1)}$. It is the most frequent severe bacterial infection in pediatric populations, especially in infants ${ }^{2}$. In a retrospective study of 5,279 febrile infants $\leq 90$ days old who presented to the emergency department of an urban hospital, $85 \%$ of the serious bacterial infections (SBIs) were due to UTIs ${ }^{3}$.

Detection of UTI remains a diagnostic challenge in neonates and very young infants. Pre-verbal neonates and infants may present with nonspecific signs and symptoms such as lethargy, prolonged jaundice, hematuria, poor feeding, vomiting, diarrhea, irritability, failure to thrive, cloudy or malodorous 
urine, and crying on passing urine ${ }^{4)}$.

While the current UTI guidelines issued by the American Academy of Pediatrics ${ }^{5,6)}$ provide guidance regarding febrile UTIs in infants and children 2-24 months old, little guidance is offered regarding febrile UTIs in those younger than 8 weeks of age. We hypothesized that neonates and young infants may have a different fever response to UTI than older children do and that fever alone may not be sensitive enough to detect all cases in this age group. They may have special characteristics that should be identifed for the establishment of guidelines in the future. The purpose of this study is to define the clinical characteristics and outcomes of the first episode of UTI in patients younger than 2 months of age.

\section{Materials and methods}

This was a retrospective single-institution study on all neonates, infants, and children younger than 24 months of age who were evaluated for the first episode of febrile or symptomatic UTI (F/SUTI) at the pediatric department of Pamela Youde Nethersole Eastern Hospital (PYNEH) in Hong Kong between July 2009 and June 2016. Our departmental guideline required all children younger than 3 years old at the time of first UTI to undergo renal and bladder ultrasound scan (USG), micturating cystourethrography scan (MCUG), and ${ }^{99 \mathrm{~m}}$ Technetium-dimercaptosuccinic acid scintigraphy scan (DMSA).

UTI was defined as significant bacterial growth $\left(\geq 10^{5}\right.$ colony-forming units per millilitre [CFU/mL] or $10^{4-5} \mathrm{CFU} /$ $\mathrm{mL}$ with increased pyuria $[\geq 10$ white blood cells per microlitre in uncentrifuged urine]) of a single uropathogen in a urine sample obtained using an appropriate method, such as by suprapubic aspirate (SPA) or urinary catheterization $(\mathrm{CSU})^{5-9)}$. For SPA, a bacterial growth of $\geq 1,000 \mathrm{CFUs} / \mathrm{mL}$ was considered significant. The choice of SPA or CSU was decided by the admission doctor.

Vesico-ureteric reflux (VUR) was graded I-V according to the International Study Classification ${ }^{10,11)}$. Renal scarring was defined as focal or generalized photopenia using late DMSA scan and/or the associated loss of kidney contour or cortical thinning with reduced volume ${ }^{12)}$.

Electronic and written patient records were retrieved and reviewed for suitability according to the inclusion and exclusion criteria. We included patients with late DMSA scan performed at 9 months following acute UTI to assess renal cortical scarring. Data on patient characteristics, laboratory results from diagnostic workups, and imaging results from renal and bladder USG, MCUG, and DMSA were obtained using a standardized template. Urine cultures (CSU, SPT) with insignificant bacterial count; CSU cultures $10^{4-5} \mathrm{CFU} /$ $\mathrm{mL}$ without increased pyuria (>10 WCC/microL); urine collected using clean-catch urine (CCU), mid-stream urine (MSU), bag urine, or unknown urine collection methods; urine cultures with polymicrobial growth were excluded. Patients with major genitourinary anomalies (e.g., exstrophy of the urinary bladder, hypospadias, ambiguous genitalia); those with indwelling urinary catheter or urinary stents; those with UTIs that occurred within one week of urinary catheterization; those with prematurity by corrected age at the time of first UTI were excluded.

Independent $t$-test was used to compare the means between the two age groups. Significant results were included as predictors in the logistic regression model with age group less than 2 months old as the outcome variable. $P$-values $<0.05$ were considered statistically significant. Statistics were performed by STATA version 8 (StataCorp LP, College Station, TX, USA).

This study was approved by the Cluster Research Ethics Committee/Institutional Review Board ("REC/IRB") of the Hong Kong East Cluster, Hospital Authority. The patients' informed consent was waived.

\section{Results}

Among the 314 children of all ages with first episode of UTI who were investigated during the study period at our institution, 287 children were younger than 24 months of age. Ninety-five children were excluded using the selection criteria, and the data of the remaining 192 children were used for the statistical analyses. Twenty-nine out of 192 children (15.1\%) were younger than 2 months of age. The mean age was $5.8 \pm 4.8$ months and $58.2 \%$ were males. All 192 children underwent USG and DMSA scans, and MCUG was performed in 174/192 children (90.6\%). The overall prevalence rates of abnormal USG finding, VUR, recur- 
rence of UTI and renal scarring were 19.8\%, 21.8\%, 24.0\% and $10.4 \%$ respectively.

Four infants younger than 2 months of age had symptomatic non-febrile UTI, and they presented with the following symptoms: prolonged and conjugated hyperbilirubinemia; neonatal jaundice requiring triple phototherapy; reduced feeding and lethargy; tachycardia with heart rate $>200$ beats per minute. Three children older than 2 months of age had symptomatic non-febrile UTI, and they presented with the following symptoms: chills and rigors; failure to thrive; hematuria.

Neonates and infants younger than 2 months of age were significantly less likely to develop fever $(86.2 \%$ vs. $98.2 \%$, $P=0.001)$ and had significantly lower fever peaks $\left(38.3^{\circ} \mathrm{C}\right.$

Table 1. Comparison of Clinical Characteristics and Outcomes of First Episode of UTI

\begin{tabular}{|c|c|c|c|}
\hline & $\begin{array}{c}<2 \\
\text { months old }\end{array}$ & $\begin{array}{c}2-24 \\
\text { months old }\end{array}$ & \multirow{2}{*}{$\begin{array}{c}P_{-} \\
\text {value }\end{array}$} \\
\hline & Mean (SD) & Mean (SD) & \\
\hline \multicolumn{4}{|l|}{ Patient Characteristics } \\
\hline Male gender & $69.0 \%(0.47)$ & $56.3 \%(0.50)$ & 0.203 \\
\hline Maturity at delivery (weeks) & $38.6(1.28)$ & $38.4(2.02)$ & 0.641 \\
\hline Birth weight (grams) & $3,065.0(480.08)$ & $3,040.8(521.79)$ & 0.822 \\
\hline History of prematurity* & $3.6 \%(0.19)$ & $11.2 \%(0.32)$ & 0.220 \\
\hline \multicolumn{4}{|l|}{ IIIness Characteristics } \\
\hline Temperature $\geq 38^{\circ} \mathrm{C}$ & $86.2 \%(0.35)$ & $98.2 \%(0.13)$ & $0.001^{*}$ \\
\hline $\begin{array}{l}\text { Maximum temperature } \\
\text { (Tmax) }\end{array}$ & $38.3^{\circ} \mathrm{C}(0.68)$ & $39.4^{\circ} \mathrm{C}(0.85)$ & $<0.001^{*}$ \\
\hline $\begin{array}{l}\text { Duration of fever before } \\
\text { admission (days) }\end{array}$ & $1.2(1.10)$ & $2.0(1.46)$ & $0.003^{*}$ \\
\hline $\begin{array}{l}\text { Duration of fever after } \\
\text { antibiotics (days) }\end{array}$ & $0.6(0.57)$ & $1.2(0.97)$ & $<0.001^{*}$ \\
\hline Length of stay (days) & $11.8(7.57)$ & $7.4(8.04)$ & $0.007^{*}$ \\
\hline \multicolumn{4}{|l|}{ Laboratory Results } \\
\hline Non-E coli uropathogen & $27.6 \%(0.45)$ & $9.8 \%(0.30)$ & $0.008^{*}$ \\
\hline $\begin{array}{l}\text { ESBL producing } \\
\text { uropathogens }\end{array}$ & $11.1 \%(0.32)$ & $12.4 \%(0.33)$ & 0.848 \\
\hline Septicemia & $6.9 \%(0.26)$ & $3.7 \%(0.19)$ & 0.437 \\
\hline Meningitis & $5.9 \%(0.24)$ & $0.0 \%(0.00)$ & 0.411 \\
\hline $\mathrm{CRP}(\mathrm{mg} / \mathrm{L})$ & $43.5(37.33)$ & $72.0(57.93)$ & $0.012^{*}$ \\
\hline WBC $\left(\times 10^{9} / \mathrm{L}\right)$ & $18.0(8.04)$ & $17.7(6.51)$ & 0.569 \\
\hline ANC $\left(\times 10^{9} / L\right)$ & $11.4(6.15)$ & $10.4(5.27)$ & 0.395 \\
\hline \multicolumn{4}{|l|}{ Outcome } \\
\hline USG abnormality & $27.6 \%(0.45)$ & $18.4 \%(0.39)$ & 0.255 \\
\hline VUR & $27.6 \%(0.45)$ & $20.7 \%(0.41)$ & 0.415 \\
\hline Recurrence of UTI & $37.9 \%(0.86)$ & $21.5 \%(0.65)$ & 0.237 \\
\hline Renal scarring & $10.3 \%(0.31)$ & $10.4 \%(0.31)$ & 0.989 \\
\hline
\end{tabular}

*All premature babies reached $\geq 37$ weeks by corrected age at the time of first episode of UTI. vs. $39.4^{\circ} \mathrm{C}, P<0.001$ ) (Table 1$)$. The difference in fever peak between the two age groups remained significant irrespective of whether it was an axillary, tympanic, or rectal temperature (Table 2). Furthermore, the duration of fever before admission (1.2 days vs. 2.0 days, $P=0.003$ ) and after starting antibiotics ( 0.6 days vs. 1.2 days, $P<0.001$ ) was significantly shorter. This age group was also associated with a significantly longer hospitalization period (11.8 days vs. 7.4 days, $P=0.007)$.

C-reactive protein (CRP) was significantly lower (43.5 vs. $72.0 \mathrm{mg} / \mathrm{L}, P=0.012)$ in infants younger than 2 months of age, but there was no difference in white blood cells (WBC) or absolute neutrophil count (ANC). Non-E coli infection was significantly more common in infants younger than 2 months of age ( $27.6 \%$ vs. $9.8 \%, P=0.008)$, which included 5 cases of Klebsiella infection and 3 cases of Enterococcus infection. There was no difference in the prevalence of extended-spectrum beta-lactamases(ESBL)-producing uropathogen in the two age groups.

Septicemia was more frequent in infants younger than 2 months of age, but the difference was not statistically significant (6.9\% vs. $3.7 \%, P=0.437)$. There was one case (5.9\%) of aseptic meningitis and Enterococcus UTI diagnosed in a 1-month-old infant.

There were no differences in the prevalence of USG abnormality, VUR, recurrence of UTI, or renal scarring.

Among the significant characteristics that were further analyzed by logistic regression (Table 3 ), only maximum body temperature (adjusted OR=0.15; 95\% CI 0.05-0.48; $P=0.001$ ) and non- $E$ coli infection (adjusted $\mathrm{OR}=17.20$; 95\% CI 3.26-90.77; $P=0.001$ ) remained statistically signifi-

Table 2. Analysis of Fever Peak by Method of Body Temperature Measurement

\begin{tabular}{|c|c|c|c|c|c|}
\hline & \multicolumn{2}{|c|}{$<2$ months old } & \multicolumn{2}{|c|}{ 2-24 months old } & \multirow{2}{*}{$\begin{array}{c}P_{-} \\
\text {value }\end{array}$} \\
\hline & $\begin{array}{l}\text { Mean } \\
(95 \% \text { Cl) }\end{array}$ & $\mathrm{N}$ & $\begin{array}{c}\text { Mean } \\
(95 \% \mathrm{Cl})\end{array}$ & N & \\
\hline Tympanic temperature ( $\left.{ }^{\circ} \mathrm{C}\right)$ & $\begin{array}{c}38.5 \\
(38.3-38.6)\end{array}$ & 11 & $\begin{array}{c}39.6 \\
(39.4-39.8)\end{array}$ & 82 & $<0.001^{*}$ \\
\hline Axillary temperature $\left({ }^{\circ} \mathrm{C}\right)$ & $\begin{array}{c}38.1 \\
(37.4-38.9)\end{array}$ & 9 & $\begin{array}{c}38.9 \\
(38.5-39.3)\end{array}$ & 15 & $0.037^{*}$ \\
\hline Rectal temperature $\left({ }^{\circ} \mathrm{C}\right)$ & $\begin{array}{c}38.6 \\
(37.5-39.7)\end{array}$ & 4 & $\begin{array}{c}39.5 \\
(39.0-40.0)\end{array}$ & 11 & $0.047^{*}$ \\
\hline Unrecorded $\left({ }^{\circ} \mathrm{C}\right)$ & $\begin{array}{c}38.5 \\
(37.5-39.4)\end{array}$ & 5 & $\begin{array}{c}39.1 \\
(38.8-39.4)\end{array}$ & 40 & 0.115 \\
\hline Total & & 29 & & 148 & \\
\hline
\end{tabular}

*Statistically significant at $P<0.05$. 
cant after multivariate adjustment.

Among the 192 children younger than 24 months of age, increased pyuria ( $\geq 10 \mathrm{WBCs} / \mu \mathrm{L})$ at diagnosis was significantly more common in $E$ coli infection than in non- $E$ coli infection $(92.2 \%$ vs. $66.7 \%, \mathrm{P}<0.001)$. Proteus infection was significantly less likely to show increased pyuria than was non-Proteus infection (33.3\% vs. $89.9 \%, P=0.002)$. There was no significant difference in pyuria response at the time of diagnosis in Klebiella and Enterococcus infection when compared to non-Klebsiella ( $90.9 \%$ vs. $88.9 \%, P=0.836$ ) and non-Enterococcus $(80.0 \%$ vs. $89.2 \%, P=0.517)$ infections, respectively.

Of the 29 infants younger than 8 weeks of age, 2 (6.9\%) had an occasional pyuric response (3-9 WBCs/ $\mu \mathrm{L}), 11$ (37.9 $\%$ ) had an increased pyuric response (10-50 WBCs/ $\mu \mathrm{L})$, and the remaining $16(55.2 \%)$ had a numerous pyuric response ( $>50 \mathrm{WBCs} / \mu \mathrm{L}$ ) at diagnosis. The prevalence of increased pyuria stratified by age group and uropathogen is shown in Table 4. There was no difference in the level at diagnosis in infants younger than 8 weeks of age when compared to those aged 2-24 months for each of the uropathogens tested.

Table 3. Multivariate Logistic Regression of the $<2$ Months Old Age Group

\begin{tabular}{lcl}
\hline & \multicolumn{2}{c}{ Multivariate } \\
\cline { 2 - 3 } & OR $(95 \% \mathrm{Cl})$ & $P$-value \\
\hline Fever peak & $0.15(0.05-0.48)$ & $0.001^{*}$ \\
Duration of fever before admission & $0.66(0.37-1.21)$ & 0.182 \\
Duration of fever after antibiotics & $0.64(0.23-1.75)$ & 0.383 \\
Length of stay & $1.02(0.98-1.07)$ & 0.343 \\
CRP & $1.01(0.99-1.02)$ & 0.424 \\
Non-E coli infection & $17.20(3.26-90.77)$ & $0.001^{*}$ \\
\hline
\end{tabular}

* Statistically significant at $P<0.05$.

Table 4. Increased Pyuria Response ( $>10 \mathrm{WBCs} / \mu \mathrm{L})$ in different Uropathogens by Age Groups

\begin{tabular}{|c|c|c|c|c|c|}
\hline & \multicolumn{2}{|c|}{$<2$ months old } & \multicolumn{2}{|c|}{ 2-24 months old } & \multirow{2}{*}{$\begin{array}{c}P_{-} \\
\text {value }\end{array}$} \\
\hline & $\begin{array}{l}\text { Mean \% } \\
(95 \% \text { Cl) }\end{array}$ & $\mathrm{N}$ & $\begin{array}{l}\text { Mean \% } \\
(95 \% \text { Cl) }\end{array}$ & $\mathrm{N}$ & \\
\hline Ecoli infection & $\begin{array}{c}95.2 \\
(85.3-105.2)\end{array}$ & 21 & $\begin{array}{c}91.8 \\
(87.3-96.3)\end{array}$ & 146 & 0.583 \\
\hline Non-E coli infection & $\begin{array}{c}87.5 \\
(57.9-117.1)\end{array}$ & 8 & $\begin{array}{c}56.3 \\
(28.9-83.6)\end{array}$ & 16 & 0.137 \\
\hline Enterococcus infection & $\begin{array}{c}66.7 \\
(-76.8-210.0)\end{array}$ & 3 & $\begin{array}{c}100.0 \\
(100.0- \\
100.0)\end{array}$ & 2 & 0.495 \\
\hline Klebsiella infection & $\begin{array}{c}100.0 \\
(100.0-100.0)\end{array}$ & 5 & $\begin{array}{c}83.3 \\
(40.5-126.2)\end{array}$ & 6 & 0.389 \\
\hline
\end{tabular}

\section{Discussion}

The lower prevalence of fever and lower maximum body temperature are curious findings that have implications on future diagnostic criteria of UTI in infants younger than 8 weeks of age, though they are consistent with the current understanding that neonates can exhibit fever, temperature instability, and even hypothermia in response to infection. Although the $1^{\circ} \mathrm{C}$ difference in fever peak may be explained by the different methods of body temperature measurement (e.g., axillary temperature being $2^{\circ} \mathrm{C}$ lower than rectal), this was not the case upon further analysis (Table 2). The shorter duration of fever before admission may be attributed to the increased eagerness on the part of caregivers and primary health practitioners to bring younger infants to the hospital for treatment. However, the more rapid response to antibiotic therapy remains unexplained. CRP was found to be significantly lower in infants younger than 2 months of age. This finding should be interpreted with caution, and its validity needs to be confirmed with future studies. CRP has the advantage of being relatively independent of age and gender over erythrocyte sedimentation rate (ESR). Moreover, the CRP reference value changes only minimally from neonates to the elderly ${ }^{13)}$. Hence, our hospital laboratory uses a uniform CRP reference value of $\leq 5.0 \mathrm{mg} / \mathrm{L}$ across different age groups. However, more recent studies have shown that CRP can be influenced by gestational age at birth and even by age itself. In newborns, a CRP value $>60$ $\mathrm{mg} / \mathrm{L}$ was more likely to occur with increasing gestational $\operatorname{age}^{14)}$. In older individuals $>4$ years of age, the upper reference limit of CRP was found to be influenced by age ${ }^{15)}$. This may explain why an earlier study did not find CRP to be a sensitive index for UTI in febrile infants younger than 8 weeks of age. It had a sensitivity of $59 \%$ and a specificity of $90 \%$ in detecting UTI at CRP $>20 \mathrm{mg} / \mathrm{L}^{16)}$.

In the present study, the rate of comorbid septicemia (6.9 $\%$ ) was similar to the $7 \%$ reported in febrile infants younger than 3 months of age in another study ${ }^{17)}$, although an earlier study had reported rates of up to $30 \%$ in similar age groups

${ }^{18)}$. In accordance with that study ${ }^{18)}$, we did not identify enough cases of meningitis to enable a meaningful analysis.

There is some controversy regarding the definition of UTI in infants younger than 8 weeks of age, and no ideal microbiological standard has been established to accurately 
define UTI in neonates younger than 30 days of age ${ }^{7}$. For febrile infants younger than 8 weeks of age presenting at an emergency department, urinalysis results suggestive of UTI have been defined as $>5$ WBCs per high-power field or the presence of any bacteria ${ }^{19}$. In another study on febrile infants aged younger than 8 weeks, growth of a single uropathogen of $\geq 100 \mathrm{CFU} / \mathrm{mL}$ was considered diagnostic of $\mathrm{UTI}^{16)}$. In a study on febrile infants aged 0-3 months, UTI was defined by the growth of $\geq 10^{5} \mathrm{CFU} / \mathrm{mL}$ in urine culture ${ }^{17}$. To the best of our knowledge, we used the UTI definition that was most commonly used in research protocols: growth of a single uropathogen with $\geq 50,000 \mathrm{CFU} / \mathrm{mL}$, or between 10,000 and $50,000 \mathrm{CFU} / \mathrm{mL}$ with associated pyuria detected on urinalysis ${ }^{5-9)}$.

While the hospital laboratories of the Hospital Authority in Hong Kong reported bacterial growth as " $10^{3-4} \mathrm{CFU} / \mathrm{mL}$ ", " $10^{4-5} \mathrm{CFU} / \mathrm{mL}$ ", " $10^{>5} \mathrm{CFU} / \mathrm{mL}$ " etc., the AAP defined significant bacterial growth as $\geq 50,000 \mathrm{CFU} / \mathrm{mL}$ (i.e., the midpoint value of $10^{4-5} \mathrm{CFU} / \mathrm{mL}$ ). Hence, we included only cases with $10^{4-5} \mathrm{CFU} / \mathrm{mL}$ that also had elevated pyuria, in line with the recommendation that cases with 10,000 to $100,000 \mathrm{CFUs} / \mathrm{mL}$ needed to be evaluated in the context of urinalysis and urine culture results ${ }^{5}$. Hence, our UTI definition was more stringent in that cases with 50,000 to $100,000 \mathrm{CFU} / \mathrm{mL}$ were required to show associated pyuria.

Symptomatic non-febrile UTI was relatively uncommon in this study (3.6\%, 7/192 cases). It could be contended that they were misdiagnosed because of contaminated urine specimens or asymptomatic bacteriuria, but this is unlikely as there was concomitant pyuria and they all presented with symptoms consistent with infantile UTI. Because of the small number of cases, it is unlikely that including them in our analysis led to a bias in our results.

Pyuria is present in cases of true UTI, which helps to distinguish it from contaminated urine specimens or asymptomatic bacteriuria ${ }^{5}$. However, it does occur less frequently in neonates and in non- $E$ coli UTIs. In a prospective study that enrolled 162 febrile infants younger than 8 weeks of age ${ }^{16)}$, only 18 (81.8\%) of the 22 infants with UTI (prevalence $13.6 \%$ ) had pyuria $\geq 10 \mathrm{WBCs} / \mu \mathrm{L}$. In another study, only $79 \%$ of neonates were positive for leukocyte esterase (marker for pyuria) or nitrites (marker of bacteriuria) on urinary dipstick ${ }^{7}$. A previous study demonstrated that the frequency of pyuria was lower in Enterococcus
(54.3\%), Klebsiella (73.9\%), and Pseudomonas aeruginosa (61.5\%) UTIs compared to $E$. coli UTIs (89.3\%), and it was suggested that a diagnosis of UTI could be made when infected by those organisms, even without pyuria ${ }^{20)}$. Our study yielded similar rates of increased pyuria response in Enterococcus (80.0\%), Klebsiella (90.9\%), and E. coli (92.2 $\%$ infections. Our results indicate that infants younger than 8 weeks of age can generate an adequate pyuric response to different uropathogens (Table 4), as only less than $7 \%(2 / 29)$ of the children did not have elevated levels of pyuria.

Most existing studies on UTI in infants younger than 8 weeks of age did not include renal imaging ${ }^{16,19)}$, whereas others only performed USG and MCUG, but not DMSA ${ }^{7}$ ${ }^{17)}$. One limitation of our study was its small sample size, though it was comparable to another study that performed DMSA $^{211}$. A meta-analysis on pediatric patients aged 0-18 years showed older age groups to be at higher risk of renal scarring, but it excluded studies with only neonates and infants aged younger than 2 months ${ }^{22)}$. A strength of the present study lies in the inclusion of USG, MCUG, and DMSA that demonstrated similar rates of USG abnormality, VUR, and renal scarring in the children younger than 2 months of age. It can be argued that existing recommendations ${ }^{5,6)}$ on renal imaging in febrile infants 2-24 months old can be extended to infants younger than 8 weeks of age, although further research is needed to support this. The main difference between those age groups may lie in the blunted fever and CRP response in infants younger than 8 weeks of age.

Nosocomial UTI (NUTI) in childhood is reported in neonatal (NICU) ${ }^{23)}$ and pediatric intensive care units $(\mathrm{PICU})^{24}$, and urinary catheterization is a major risk factor. As our hospital offers NICU and PICU services in addition to general pediatric services (including urinary catheterization for MCUG), we excluded UTI that occurred within 1 week of urinary catheterization, as well as premature neonates at the time of first UTI because they are often catheterized in the NICU as part of the septic workup and they are relatively immunocompromised due to immaturity of their immune system and decreased placental passage of maternal antibodies ${ }^{25}$. Patients with major genitourinary anomalies are often catheterized and were also excluded.

CCU and MSU samples were excluded because the AAP 
guideline $^{5,6)}$ strongly recommends that a diagnosis of UTI should be confirmed with urine specimens obtained through SPA or CSU. This might explain why the children excluded from our analysis tended to be young male infants in whom clean-catch and mid-stream sampling might be easier to obtain than in female infants. Of the 23 infants excluded because of either CCU or MSU, 18 (78.3\%) were male infants.

We did not collect information on the use of antipyretics or external cooling (like tepid-water sponging or cooling gel pads over forehead) at home. We generally advised parents to bring young infants with a fever to the hospital for a full septic workup and did not prescribe antipyretics owing to the potential for serious bacterial infections to be masked. Hence, we would expect higher temperatures in young infants if these were confounding factors, but this was not found to be the case. While the missing data on the method of body temperature measurement was another limitation, the observed lower fever peak in infants younger than 8 weeks of age appeared genuine since it was demonstrated consistently across the axillary, tympanic, and rectal temperatures.

In conclusion, the fever and CRP response may be blunted in UTIs in neonates and infants younger than 8 weeks of age. The pyuric response to infection appears to be adequate in this age group, and a significant urine culture remains the most reliable diagnostic tool, though there is always the possibility for it to be disregarded as a contaminated specimen or asymptomatic bacteriuria. The ideal microbiological standards and consensus for the diagnosis of UTI in very young infants remain unknown, leaving room for future research. Future clinical guidelines should include significant urine culture and increased levels of pyuria as core diagnostic criteria and deemphasize the diagnostic value of fever in this age group. Recommendations for the use of renal imaging following first UTI may be extended from the older age group in view of similar rates of USG abnormality, VUR, and renal scarring.

\section{Conflicts of interest}

No potential conflict of interest relevant to this article was reported.

\section{Acknowledgements}

I wish to thank the clinicians who treated the children over the years and laid down the foundation of today's research. I wish to thank Dr. Elaine Yin-Wah Kwan, Dr. Robert Shing-Yan Lee, Dr. Wing-Cheong Lee, and the journal reviewers for their valuable comments after reading this manuscript. I also wish to thank the Department of Radiology and Department of Nuclear Medicine at PYNEH for their information on renal imaging.

\section{References:}

1. Lee YJ, Lee JH, Park YS. Risk factors for renal scar formation in infants with first episode of acute pyelonephritis: a prospective clinical study. J Urol 2012;187(3):1032-6.

2. An YK, Cho MH, Kim KS. Which factors related to the renal cortical defects in infants under 3 months of age with urinary tract infections? Child Kidney Dis 2016;20(2):57-62.

3. Bachur RG, Harper MB. Predictive model for serious bacterial infections among infants younger than 3 months of age. Pediatrics 2001;108(2):311-6.

4. Tsai JD, Lin CC, Yang SS. Diagnosis of pediatric urinary tract infections. Urol Sci 2016;27(3):131-134.

5. Subcommittee on Urinary Tract Infection, Steering Committee on Quality Improvement and Management, Roberts KB. Urinary tract infection: clinical practice guideline for the diagnosis and management of the initial UTI in febrile infants and children 2 to 24 months. Pediatrics 2011;128(3):595-610.

6. Subcommittee on Urinary Tract Infection. Reaffirmation of AAP Clinical Practice Guideline: The Diagnosis and Management of the Initial Urinary Tract Infection in Febrile Infants and Young Children 2-24 Months of Age. Pediatrics 2016;138(6).

7. Bonadio W, Maida G. Urinary tract infection in outpatient febrile infants younger than 30 days of age: a 10-year evaluation. Pediatr Infect Dis J 2014;33(4):342-4.

8. Hoberman A, Wald ER, Reynolds EA, Penchansky L, Charron M. Pyuria and bacteriuria in urine specimens obtained by catheter from young children with fever. J Pediatr 1994;124(4):513-9.

9. Hoberman A, Wald ER. Urinary tract infections in young febrile children. Pediatr Infect Dis J 1997;16(1):11-7.

10. International Reflux Study Committee. Medical versus surgical treatment of primary vesicoureteral reflux: report of the International Reflux Study Committee. Pediatrics 1981;67:392-400.

11. Lebowitz RL, Olbing H, Parkkulainen KV, Smellie JM, TamminenMöbius TE. International system of radiographic grading of vesicoureteric reflux. International Reflux Study in Children. Pediatr Radiol 1985;15(2):105-9. 
12. Mandell GA, Eggli DF, Gilday DL, Heyman S, Leonard JC, Miller $\mathrm{JH}$, Nadel HR, Treves ST. Procedure guideline for renal cortical scintigraphy in children. Society of Nuclear Medicine. J Nucl Med 1997;38(10):1644-6.

13. Jaye DL, Waites KB. Clinical applications of C-reactive protein in pediatrics. Pediatr Infect Dis J 1997;16(8):735-46.

14. Turner MA, Power S, Emmerson AJ. Gestational age and the $C$ reactive protein response. Arch Dis Child Fetal Neonatal Ed 2004; 89(3):F272-3.

15. Wener MH, Daum PR, McQuillan GM. The influence of age, sex, and race on the upper reference limit of serum C-reactive protein concentration. J Rheumatol 2000;27(10):2351-9.

16. Lin DS, Huang SH, Lin CC, Tung YC, Huang TT, Chiu NC, Koa HA, Hung HY, Hsu CH, Hsieh WS, Yang DI, Huang FY. Urinary tract infection in febrile infants younger than eight weeks of age. Pediatrics 2000;105(2):E20.

17. Ismaili K, Lolin K, Damry N, Alexander M, Lepage P, Hall M. Febrile urinary tract infections in 0- to 3-month-old infants: a prospective follow-up study. J Pediatr 2011;158(1):91-4.

18. Bachur R, Caputo GL. Bacteremia and meningitis among infants with urinary tract infections. Pediatr Emerg Care 1995;11(5):2804.
19. Crain EF, Gershel JC. Urinary tract infections in febrile infants younger than 8 weeks of age. Pediatrics 1990;86(3):363-7.

20. Shaikh N, Shope TR, Hoberman A, Vigliotti A, Kurs-Lasky M, Martin JM. Association Between Uropathogen and Pyuria. Pediatrics 2016;138(1).

21. Goldman M, Lahat E, Strauss S, Reisler G, Livne A, Gordin L, Aladjem M. Imaging after urinary tract infection in male neonates. Pediatrics 2000;105(6):1232-5.

22. Shaikh N, Craig JC, Rovers MM, Da Dalt L, Gardikis S, Hoberman A, Montini G, Rodrigo C, Taskinen S, Tuerlinckx D, Shope T. Identification of children and adolescents at risk for renal scarring after a first urinary tract infection: a meta-analysis with individual patient data. JAMA Pediatr 2014;168(10):893-900.

23. Weems MF, Wei D, Ramanathan R, Barton L, Vachon L, Sardesai S. Urinary tract infections in a neonatal intensive care unit. Am J Perinatol 2015;32(7):695-702.

24. Matlow AG, Wray RD, Cox PN. Nosocomial urinary tract infections in children in a pediatric intensive care unit: a follow-up after 10 years. Pediatr Crit Care Med 2003;4(1):74-7.

25. Camacho-Gonzalez A, Spearman PW, Stoll BJ. Neonatal infectious diseases: evaluation of neonatal sepsis. Pediatr Clin North Am 2013;60(2):367-89. 